\title{
Credit Pit Detection in Subordinate Securities: A French Perspective
}

\author{
Sfoorti Jain*
}

\section{Abstract}

The purpose of this research is to prepare a predictive model for identifying credit crisis using an artificial neural network. The paper also aims to find out the driver and driven relationship between various financial instruments like CDS, FRA, IRS, and the Volatility index (VCAC) and government securities for France. The model, thus, is directed towards finding a threshold for credit pit events and linking various events corresponding to that dates where the threshold is breached to validate the accuracy and usefulness of the model. From the research, it is found that for France, the CDS-FRA-VCAC model derives the threshold for VCAC to indicate the probability of credit crisis or financial market crash. It is also found that sovereign bonds have a huge impact on France economy including various derivatives. This is probably why the Eurozone debt crisis impacted France much more than the 2008 financial crash.

Keywords: Artificial Neural Network, Granger causality, Credit Pit, Financial Crisis, Derivatives, Predictive Modeling

\section{Introduction}

The credit crash, leading to financial collapse, in 2008 has created terror of credit risk across the world. The collapse of Lehman Brothers is one example of the force of credit crash which impacted all the sectored in varying degree of losses across the globe.

\footnotetext{
* Associate Analyst-Business Analysis- Envision Financial Systems Pvt. Ltd., Bangalore, India; Sfoortijain12@gmail.com
} 
Eurozone suffered the impact equally drastically. France, however, though not unscathed, suffered a less severe impact of the credit phenomenon of 2008. Does this indicate the ability of France to withstand further credit crashes? To recover from such magnitude of the financial crisis (as that of 2008), the intervention of government becomes obligatory. And as such, sovereign debt has been sought after market post the crisis in almost all the economies. Credit market, previously associated with the public sector, impacts both forms of business (public and private) as proved in the aftermath of the crisis.

As only diamond can cut a diamond, to identify and prevent a credit crisis needs the understanding of what is entailed in a credit crisis. Credit Default Swaps were the main instruments of the 2008 financial disaster. As Warren Buffett says, derivatives are the instruments of mass-destruction; derivatives are important factors to analyse with regards to a financial crisis. Apart from CDS, other derivative instruments that are relevant in the case of credit risk and financial distress are Interest Rate Swaps and Forward rate agreements (Errico \& Battiston, 2017), especially for banks.

\subsection{Major Concepts in the Study}

Credit Default Swap (CDS), in the views of (Fontana \& Scheicher, 2010), is an insurance instrument which is used to mitigate credit risk. As agreed by York (2011), protection seller bears the risk of losses in case of credit defaults while the protection buyer pays the premium as the fee for the instrument to the seller. The CDS contracts are deemed completed or are terminated in case of any credit event. In the view of Dickinson (2008), CDS can lead to a systematic crisis in the whole economy by engaging in asset bubbles and resulting in failure of large institutions or disrupt the laws made for prevention of financial crisis.

While CDS is a tool against Credit risk, Forward rate agreement (FRA) is used to safeguard/hedge against the future movements in interest rates. FRA is a type of interest rate derivative. FRA buyer enters the agreement believing in the increase of interest rates in future and thus wants to lock the interest rate early on to manage the borrowing cost, while, on other hand, FRA seller banks upon 
the notion of interest rates falling down in future and wants to lock the rates to safeguard the returns on the investment/deposits.

\subsection{About French Economy}

Since the emergence of capitalism, France has been a capitalist nation. This European nation has been liberal with an overwhelming foundation of socialism in its governance and administrative approach concerning the economy. This indicates their unwillingness to regulate any type of financial institutes and financial markets. Financial system in the French economy is not easily classified into clusters. As highlighted by Howarth (2013), though it contains structures of deregulated, liberalised and a British framework of progressively capital market, yet it also contains the more regulated, secured bank credit related aspects from Southern Europe and Germany's Financial systems. It is because of these features of the French economy that it has handled the previous financial crisis better than other economies in the world. Etienne (2009) studied the impact of the 2008 crisis on France economy. In the course of recent years (2008-2016), the sluggishness of the French economy has been its prime feature of growth, despite the fact that the country has characteristically high resistance to shock and stress-inducing events like that of financial crisis 2008 or sovereign debt crisis of Europe in 2011-2012. Despite facing the recession in 2008, French GDP managed to return to its previous state by 2011, while the other economies of Eurozone suffered the bearish impact on their economies till tale 2015 (Baudchon, 2017).

As is to be understood from the behaviour of French economy during past two decades, when global economies collapsed and suffered dear losses, it is indeed a matter of curiosity as well as an indication for further research to figure out whether a financial crisis is a possible predictable scenario in France or is it immune to any such advancement. While (Ghosh, 2017) researched in the similar field of study for the German economy in relation to the turbulent political and economic scenarios (Brexit, Syrian migration, Greece crisis, etc) engulfing the whole of Eurozone, France still remains a research gap as to understand its queer behaviour towards such crisis. Thus, this study aims to provide a 
predictive model for bracing against credit crisis by uncovering the relations among financial instruments that are crucial in cases of credit crisis like Credit Default Swaps (CDS), Forward Rate Agreements (FRA), Interest Rate Swaps (IRS), sovereign bonds, etc.

\section{Literature Review}

A thematic review of various literature has been done for this study. Financial bubbles/crisis is one of the major drivers of crumbling of economic strategies, policies and institutes. These events lead the financial markets and economies to blast on itself and thus making delays in recuperation (Fernández-Villaverde, Garicano, \& Santos, 2013). To postpone the reforms and policies, the debt component is heavily used throughout the economic system by the potential defaulting agents. Similar things happened when the credit crisis of 2008 began. Extensive studies have been done related to this particular event by various researchers (Brunnermeier, 2008; Taylor, 2009) aiming to find out either the sequence of events, the causes, the failure, the impact or the precautionary measures for further such crisis. As studied by (Brunnermeier, 2008), the default risk on credit and its infection to other areas tuned into a major worry for law/policy makers and the banking system in the economies. Thus, many of the financial institutes became distressed to the point that they turned into a danger to global and domestic banking systems. In turn, risk transfer from many domestic banks' balance sheets to public sector balance sheets became a bailout and safeguarding option adopted by few governments.

Economists have commonly held that financial derivatives upsurge economic wellbeing by enabling risk-sharing among investors. These opinions undoubtedly relate to CDS. It is widely believed that CDS largely contribute to the credit crisis being over the counter traded instruments. However, Stulz (2009) is of contradictory opinion stating that the 2008 crisis was not necessarily caused by CDS or other derivatives; neither did it cause any financial institute to collapse. Instead, he argues that the fall and the crisis were due to an unexpected fall of real estate prices and highly leveraged organisations with subprime securitised investments. The financial bubble of 2008 made investors to adopt a 
critical look towards fiscal standpoints in many countries, inclusive of many economies of Eurozone (Ters \& Urban, 2016). This brought about a sharp ascent in sovereign credit spreads for various Eurozone nations. At their pinnacle, the German sovereign bonds, which had the yield spreads of only few basis points before the financial crisis, reached new heights of a few hundred basis points? In such dire conditions, the trading of credit risk insurance against Euro bonds by the means of CDS developed generously. The spreads on such derivative instruments likewise increased exponentially with increment in market interest towards these insurance instruments. This development caught the increased attention of policymakers and financial market regulators towards the market for CDS. CDS have been proven to be a harbinger of three kinds of risk, theoretically, namely Asset bubble, failure of systemically significant financial institutions and incentives to disrupt politics (Dickinson, 2008). However, many questions arise in the practical aspects of each kind of risks caused by CDS.

After 2009, European Central bank, like many other central banks, focused on cutting down the interest rates for short term, providing liquidity in euro denominations and ventured into swap arrangements pertaining to currency to manage the dollardenominated liquidity (Lane, 2012). Thereby, post-2008 crisis, another crisis emerged in Eurozone. High economic uncertainty and unpredictability due to past credit crisis resulted into sovereign debt crisis across various European nations. Ongoing worries about the default risks of European governments debt obligations has resulted in much the same scenarios as previously dealt with, i.e. increment of the spread of CDS instruments. It becomes necessary to understand what amount of the European crisis has been introduced by the United States (Wyplosz, 2010). The US has, undoubtedly endured more than Europe but not by an expansive margin due to the utilisation of the Euro as the common currency for Eurozone collectively. However, the single currency has its benefits like policymakers can worry less about drastic and sudden changes in other competitive currency and restricted spread of currency discrepancy. A pre and post-crisis (2008) detailed study, considering the European sovereign CDS (Fontana \& Scheicher, 2010) shows that global elements like global risk aversion can be related to an increase in pricing of CDS amid the 
crisis period, while pre and post-crisis time frames pricing changes in CDS are attributed to corporate CDS market.

While understanding of the determinants of the crisis is necessary, the measures of identifying and mitigating a crisis are important as well. Various studies have attempted to provide the best fit solution to alert for such a financial crisis, if not downright preventing it in the first place. Many of the proposed solutions have cross-correlation of several derivative and other instruments like CDS, Forward Rate Agreements (FRA), Interest Rate Swaps (IRS), Inflation Swaps, etc (Ghosh, 2017). Aside from that, singular forecasts also occurred in numerous works of prominence. However, nation-specific triggers for the credit crisis are sighted in very limited studies. The impact of the 2008 crisis on Overnight Indexed Swap (OIS) and Euribor, suddenly deviating from each other, is much like Zeeman Effect in the domain of physics (Bianchetti, 2011). Thus, a credit crisis can be very well identified by using a model based on the extensively used derivatives and the strongly related factors of a particular economy like the government bond spread or asset swaps etc. Yet another study (Kolstad, 2013) designed a model based on global and countryspecific risk factors. This model aims to identify whether risk pricing by the financial or derivatives market is substantially different in the debt bearing countries, like Greece, in comparison with stabilised economies of Eurozone, like France, along with describing the CDS spread. It is evident from the study that different factors relating to the CDS and bond market in Eurozone affect the Sovereign risk, which in other terms lead to the Sovereign debt crisis. Though the debt crisis is spread across the Eurozone (contains 29 countries), the sovereign risk primarily adheres to the European Union (19 countries) (Kalbaska \& Gątkowski, 2012). CDS markets of Ireland and Spain have a high influence on the CDS market of EU. On the other hand, the CDS market of UK does not significantly impact Eurozone CDS Market. Another study (Delatte, Gex, \& López-Villavicencio, 2012) done on the post-credit crisis, indicates that there is a non-linear transmission between CDS and bond markets in Eurozone. The study also showed that mutual influence among the Eurozone member countries is affected by market distress. The market distress is directly proportional to 
information dissemination between CDS and bond markets, which is dominated by the CDS market.

While Eurozone was hit by the sovereign debt crisis, Germany also imposed a short-selling ban on CDS spreads. Pu \& Zhang (2012) studied the global impact of this decision by the German government on 54 countries. It is found that though the shortselling ban was inefficient and ineffective in reducing the sovereign borrowing cost, it was successful in steadying CDS market by reducing the volatility in CDS trading markets. This momentum was, however, witnessed largely in Eurozone only. Supplementing the above view, a practical scenario is noted in Eurozone. The CDSbond basis captures the relative value between a cash bond and CDS contract of the same credit entity. The CDS bond basis should ideally be zero as both the CDS spread and bond spread represent the credit risk. However, the European banking sector was observing wide CDS bond basis in 2016 and thus widespread negative sentiments. As reported by Markit (2016), when the CDS bond- basis tightened due to ECB's decisions regarding credit risk, there was an influx of positive sentiments and immediate commodity and financial market bounce.

\section{Research Methodology}

For the purpose of preparing a model for identifying the credit pit in financial domain of France, various financial indicators' data was collected from the period of December 2013 to November 2018. This data was taken from various relevant online mediums. Sovereign bonds and CDS data of France was taken from sites like investing.com and bourserama.com, volatility index data was collected from yahoo finance and FRA and IRS data was collected from EMMI-benchmarks.

The data were selected to represent various indicators involved in the prediction of credit pit models. These parameters are the volatility index of France (VCAC- 40), CDS 60 (CDS 5 years), FRA for 6, 9 and 12 months, IRS for a day, 1 week and 2 weeks, stock index for mid and small caps (CAC- Futures), sovereign bond data for (G-sec for 1, 2, 3,5,10 years) and asset swaps. This data covers 
the relevant basis spread for 15 parameters. VCAC was the dependent variable while all others were independent variables.

\section{Methods Used}

Many linear and nonlinear time series methods exist, based on a variety of techniques including regression modelling, information theory, and dynamical systems theory (Gourévitch \& BouquinJeannès, 2006; Pereda, Quiroga, \& Bhattacharya, 2005). For the purpose of this study, two methods were used, namely, Granger Causality and Artificial Neural Networks.

\subsection{Granger Causality}

Granger causality is a statistical concept of causality that is based on prediction. According to Granger causality, if a signal $\mathrm{X} 1$ "Granger-causes" (or "G-causes") a signal X2, then past values of X1 should contain information that helps predict $X 2$ above and beyond the information contained in past values of $\mathrm{X} 2$ alone. Its mathematical formulation is based on linear regression modelling of stochastic processes (Granger, 1969).

The original formulation of G-causality gives information about linear features of signals and the application of G-causality helps in analysing stationarity. Over recent years, there has been growing interest in the use of G-causality to identify causal interactions in neural data.

\subsection{Artificial Neural Network}

Artificial neural network (ANN) is an imitation of the biological nervous system present in humans. It is multifaceted in nature, travels in two or more directions, overlapping in assemblies and above all improve effectiveness and productivity over a period of time. Like humans, ANN learns by examples, thus, it grows effective over time. However, since the memory is unreal or artificial, there is very less scope of data loss as is with humans. ANN can competently accomplish pattern recognition, data classification, and predictions (Ghosh, 2017). 
While ANNs provide a great deal of promise, they also embody much uncertainty. Researchers to date are still not certain about the effect of key factors on the forecasting performance of ANNs (Zhang, Patuwo \& Hu 1998). In this research, ANN was used by the medium of GMDH shell to prepare predictive modelling for credit pit identification.

\subsection{Research Design}

This study follows quantitative experimental research design and was aiming to identify the substantial relationship between various financial instruments that are at play in France and their cause/impact in the financial crisis. The research, in this study, was conducted in 4 phases. These phases were a mixture of various disciplines like machine learning, econometrics, behavioural finance and applied mathematics and statistics. These phases are-

1. Granger causality between the CDS, FRA and volatility index of France to establish the impact and connection among the various variables. (Driver - Driven Relationship)

2. Artificial Neural Network implementation on volatility index as dependent and financial derivatives as independent variables to prepare a predictive model

3. Finding Credit pits (thresholds)

4. Behavioural and event linking to the identified credit pits

\subsection{Data Set}

The data set was taken for the duration of 5 years (from December 2013 to November 2018) covering the major after-effects of the debt crisis in Eurozone as well as the ongoing crisis in the area. The data set contains 1252 observations per variable for 15 variables, containing 18,795 data points.

EURIBOR is Interbank Offered Rate for Eurozone. This rate has been taken as a proxy for FRA and IRS for France as the country is a prominent part of the Eurozone and the interest rate data of Eurozone directly correlates with that of PIBOR (Paris Interbank Offered Rate), France. 


\subsection{Variable Details}

The 15 variables used in this research were - VCAC, CDS 60, FRA 6, FRA 9, FRA 12, AWS12, IRS 1week, IRS 2 week, IRS 1 day, CACfutures, G-sec 12, G-sec 24, G-sec 36, G- sec 60 and G-sec 120.

VCAC - This variable represents the volatility index of CAC- 40, which is the stock market index for France. This was the only dependent variable used in this study.

CDS spread-CDS is a financial contract whereby a buyer of corporate or sovereign debt in the form of bonds attempts to eliminate possible loss arising from default by the issuer of the bonds. CDS are financial insurance against credit risk. The data of 5-year CDS for France was taken for this study.

FRA spread - In this research, FRA 6, FRA 9 and FRA 12 were taken indicating the FRA for 6 months, 9 months and 12 months respectively. FRAs are nothing but a series of Interest rate swaps.

IRS spread - An interest rate swap is a type of a derivative forward contract through which two counterparties agree to exchange one stream of future interest payments for another, based on a specified principal amount. Here, three types of IRS were taken with the maturity of 1 day, 1 week and 2 weeks.

CAC - Futures -This variable represents the data for the stock market index of France for futures.

G - Sec - Here, G-sec of France was taken for various maturity periods. Total of $5 \mathrm{G}$-sec are taken, namely, G-sec 12, G-sec 24, Gsec 36, G-sec 60 and G-sec 120, the numbers representing the maturity period in months.

AWS - AWS is a measure of credit risk and interest rate risk with respect to government bonds. AWS12 was taken as the variable representing the maturity period of 12 months for the government bond.

\subsection{Data Analysis}

As stated, there are 4 phases in this research covering various objectives of the study. These 4 phases each cover various domains 
and disciplines like applied mathematics, neural network and machine learning, econometrics, financial markets, derivatives, behavioural finance and statistics. Each phase is directed at covering the objectives of the study individually, yet is interconnected in deriving the results for the research as a whole.

\section{Phase 1 - Driver - Driven Relationship using Granger Causality}

The first phase incorporated the basic analysis of the data set as well as aimed to find out the driver-driven relationship among the variables. Out of the total 15 variables, VCAC was the dependent variable and rest all were independent variables.

Cross-correlation, calculated among the variables, showed that most of the variables have a very high correlation with each other except for the dependent variable. FRAs, IRS and short-term maturity bonds have a high positive correlation.

Furthermore, to find out the relationship between variables as to which variable derives which other variables, Granger causality test was performed on them in pairs. A total of 209 granger causes were obtained.

Hypotheses for the test are -

H0 - Variable X does not Granger Cause Variable Y

H1 - Variable X Granger Causes Variable Y

The margin of error is taken as $5 \%$ which means the Confidence Interval (CI) is $95 \%$. If the probability value is below 0.05 , the null hypothesis (H0) is rejected and alternate (H1) is accepted. Out of 209, 74 cases had more than 95\% CI. From the results, it is found that the variables with the most driving relationship with others are CDS 60, FRAs, G-sec 24, G-sec 36, G-sec 60 and IRS. A healthy presence of Derivatives impacting each other is what was expected from France. Few other observations are -

- IRS derive the majority of short-term government bonds (Gsec 12 and 24) whereas are driven by long term government bonds (G-sec 36 and 60).

- CDS is the deriver of FRAs and IRs of all maturities. 
- FRAs also derive G-sec 12 and IRS 1 day.

- The long-term G-sec also derives the short-term G-sec 12.

\section{Phase 2 - Predictive Modelling using Artificial Neural Network}

In this phase, the volatility index of France (VCAC) is subjected to predictive modelling using Artificial Neural Network. This is the method of creating a model for predicting future VCAC prices. ANN is a self-correcting method of prediction and hence is highly accurate due to its repetitive iterations for correcting itself.

The predictive model for the data is made by using GMDH Shell which works on ANN. VCAC is taken as an independent variable. While putting the data, training data is kept at $75 \%$ while the rest $25 \%$ is used as testing data to check the accuracy of prediction. Thus, the data has fairly large testing set to check the model. Every $5^{\text {th }}$ observation (7th day) is taken as testing data by using random stratified sampling.

In Figure 1, blue represents training data and red represents testing data. The diagram is not a sawtooth diagram representing that the data is fuzzy and not binary.

It is clearly visible that in most places the model is a very good fit for the actual data.

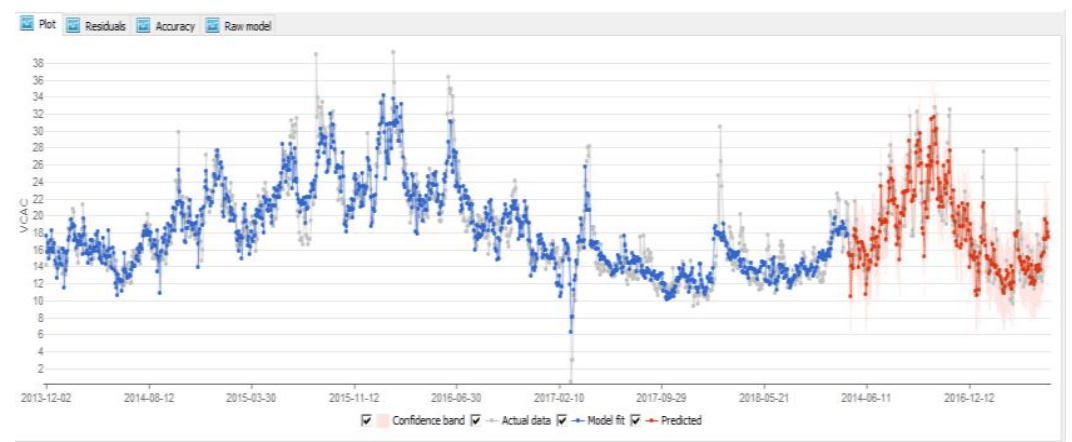

Fig1: Graphical plot of training and testing data 


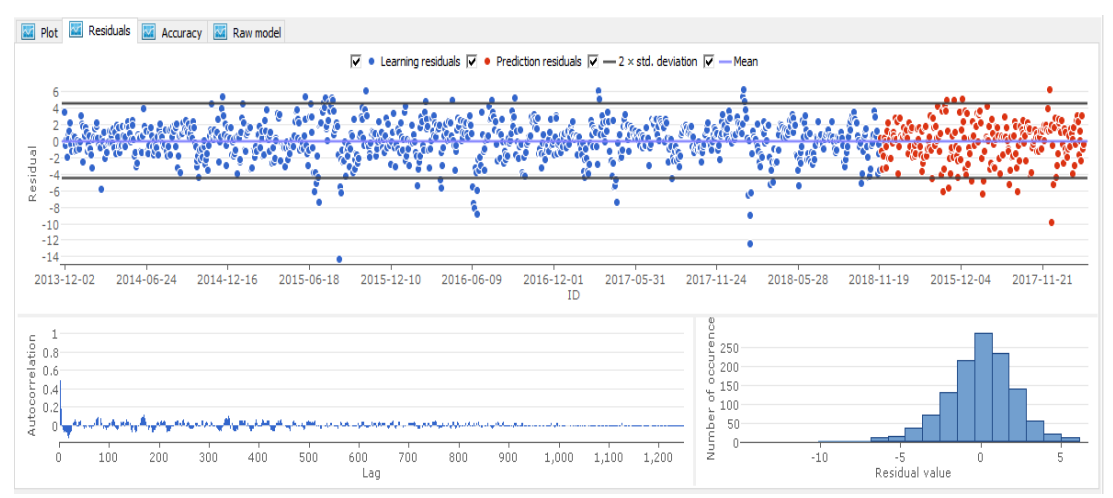

Fig 2: Residual Plot of the model

In the first graph of Figure 2, it shows that the residual plot for the model. It depicts the deviations of the predicted model from the actual data. Here, the dots which are beyond the black bands are outliers. However, it is seen that there are very few outliers in the red zone (testing zone). Thus, it suggests that predicted data is closer to actual data and the model is robust.

In the second graph, we see that the auto-correlation is drastically decreasing (when we zoom in on the graph) over the period of time. Since ACF is decreasing, it is concluded to be an autoregressive model as is the property of Neural Network.

In the third graph, we see that the histogram is without any breaks in the middle suggesting the consistency of the model over the whole period. The length of bars on histogram indicates the closeness of predicted data to actual. We see the highest bar at 0 residual, which means a large number of predicted data points are nearly or exactly equal to the actual data points.

In Figure 3, we see that model fit on training data and predicted data. This is to check the accuracy of the constructed model. However, we not only check predictions but also model fit to determine the accuracy of the overall model. Sometimes, the wrong model can also have good prediction.

Thus, in Figure 3, we see that MAE and RMSE values for both model fit and prediction are considerably low. R-square is also 
fairly high in both cases. From the generated residual data, it is seen that residuals for testing as well as training data, though are both positive and negative, do not have a very high value. This indicates the low level of deviation of the predicted model from the actual model.

\begin{tabular}{|c|c|c|c|}
\hline Plot $\triangle$ & Residuals $\mathrm{A}$ & Accuracy & (9) Raw model \\
\hline Error measure & Absolute & Targ & get: VCAC \\
\hline \multicolumn{2}{|c|}{ Postprocessed results } & Model fit & Predictions \\
\hline \multicolumn{2}{|c|}{ Number of observations } & 1002 & 250 \\
\hline \multicolumn{2}{|c|}{ Max. negative error } & -14.3622 & -9.98116 \\
\hline \multicolumn{2}{|c|}{ Max. positive error } & 6.10202 & 6.04772 \\
\hline \multicolumn{2}{|c|}{ Mean absolute error (MAE) } & 1.65227 & 1.84485 \\
\hline \multicolumn{2}{|c|}{ Root mean square error (RMSE) } & 2.21271 & 2.38503 \\
\hline \multicolumn{2}{|l|}{ Residual sum } & $3.72247 E-9$ & -32.6545 \\
\hline \multicolumn{2}{|c|}{ Standard deviation of residuals } & 2.21271 & 2.38145 \\
\hline \multicolumn{2}{|c|}{ Coefficient of determination $\left(R^{2}\right)$} & 0.829763 & 0.788727 \\
\hline \multicolumn{2}{|l|}{ Correlation } & 0.910914 & 0.888843 \\
\hline
\end{tabular}

Fig 3: Prediction accuracy of the model

Figure 4 shows the raw model of the data. The equation shown is the raw form of the variables used to predict VCAC from other dependant variables in the model.

Fig 4: VCAC Predictor Raw model

VCAC $=-372.771+(\mathrm{G}-\sec 36)^{*}(\mathrm{G}-\sec 120)^{*}(-80.2657)+\mathrm{FRA}^{*}(\mathrm{G}-\mathrm{sec} 24)^{*}(-3075.2)+(\mathrm{G}-$ sec36 $)^{*} 161.577+(\mathrm{G}-\mathrm{sec} 24)^{* \prime}$ FRA6, cubert"*101.214 + “FRA6, cubert"^2*(-154.952) + "IRS 2 weeks"*"CDS60, cubert"*194.531 + "IRS 2 weeks"*(G-sec120)*(-1396.66) + (Gsec120*333.026 + “FRA9, cubert"^2*138.487 + (G-sec36 ${ }^{* \prime}$ FRA9, cubert"*(-802.507) + $(\mathrm{G}-\sec 12) *(\mathrm{G}-\mathrm{sec} 60) *(-389.385)+$ "AWS12, cubert"*504.589 + (G-sec120)*”AWS12, cubert $^{\prime \prime *}(-339.085)+(\mathrm{G}-\mathrm{sec} 36)^{\wedge} 2 * 126.956+$ "FRA12, cubert ${ }^{\prime \prime} 2^{*} 66.7352+$ FRA12*" IRS 1 week", cubert $^{\prime *}(-1668.52)+$ AWS12*"”IRS 1 week", cubert"*755.866 + "”IRS 1 week", cubert"^2*90.1957 + "FRA6, cubert"*"”IRS 1 week", cubert"*814.502 + "IRS 2 weeks"*"FRA6, cubert"*(-698.159) + "IRS 1 week"*(G-sec120)*1023.15 + "IRS 2 weeks"^2*3927 + “CDS60, cubert"^2*(-3.58841) + (G-sec120) $)^{* \prime C D S 60, ~ c u b e r t " * 27.1242 ~}$ $+(\mathrm{G}-\mathrm{sec} 60))^{* \prime}$ FRA6, cubert"*(-288.846) + AWS12*"FRA9, cubert"*(-607.681) + (Gsec12)*"FRA12, cubert"*(-669.446) + “AWS12, cubert"*"" IRS 1 week", cubert"*($723.232)+$ "IRS 2 weeks"*548.201 + (G-sec120)*"'IRS 1 week", cubert"*204.43 + (Gsec60)*"' IRS 1 week", cubert"*(-340.273) + "IRS 1 week"*(G-sec12)*(-1183.63) + "IRS 2 weeks"*"FRA9, cubert"*(-1872.04) + "CDS60, cubert"*"'"IRS 1 week", cubert"*(-55.5469) + "IRS 1 week"*"FRA9, cubert"*1025.73 + (G-sec60)*"FRA12, cubert"*208.183 + "FRA6,

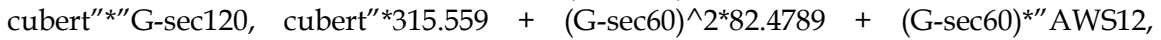


cubert"* $(-475.583)+$ "IRS 1 day"* $(\text { G-sec24 })^{*}(-271.133)+$ "IRS 1 day"* $(\mathrm{G}-\sec 12) * 228.723+$ "IRS 1 week"*(G-sec24)*1103.98 + (G-sec60)*"CDS60, cubert"*(-24.154) + (Gsec36) ${ }^{* \prime \prime \prime}$ IRS 1 day", cubert"*36.4783 + “AWS12, cubert"*"'"IRS 1 day", cubert"*15.6889 $+(\mathrm{G}-\sec 24)^{*}(\mathrm{G}-\sec 60)^{*}(-122.604)+{ }^{\prime \prime} \mathrm{IRS} 1$ week $^{\prime *}(\mathrm{G}-\sec 36)^{*}(-877.569)$ + FRA6 ${ }^{* \prime} \mathrm{G}-$ sec120, cubert"*(-1673.47) + FRA6*(G-sec60)*1148.38 + FRA6*"AWS12, cubert"*3941.55 + FRA6*AWS12*(-6029.34) + FRA9* $(-3303.17)+\left(\right.$ G-sec36) ${ }^{* \prime}$ FRA6, cubert"*436.876 + FRA12*"FRA6, cubert"*986.627 + FRA12*"FRA12, cubert"*(-1502.78) + FRA12*(Gsec12 $)^{*} 1678.68$ + FRA6*"FRA6, cubert"*(-1505.89) + FRA9*AWS12*4775.18 + "IRS 1 week"*"G-sec120, cubert $^{\prime \prime *}(-1420.9)+$ FRA6*"FRA12, cubert"*1681.32 + (Gsec24)*"CDS60, cubert"*23.2348 + “IRS 2 weeks"*(G-sec36)*192.441 + "IRS 2 weeks"*"G-sec120, cubert"*1866.43 + "IRS 1 week"*"'"IRS 1 week", cubert"*(-551.373) + FRA9*"CDS60, cubert"*(-134.593) + "IRS 1 week"*"IRS 2 weeks"*(-6226.84) + "IRS 1 week" $^{\prime \prime} 2 * 3747.31+$ FRA6" IRS 2 weeks"*5330.41 + "FRA6, cubert"*"FRA9, cubert"*364.548 + "FRA12, cubert"*"G-sec120, cubert"*(-140.178) + (G-sec120)*"Gsec120, cubert"*(-82.8272) + FRA6*"IRS 1 week $^{\prime \prime *}(-3201.81)+(\mathrm{G}-\mathrm{sec} 24)^{* \prime \prime \prime \prime}$ IRS 1 week",

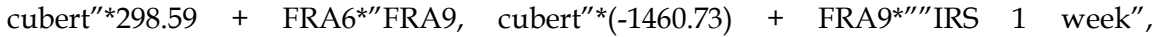
cubert" ${ }^{\prime *} 939.98+$ FRA9^$^{\wedge}{ }^{*}(-3662.79)+$ FRA12*1862.82 + FRA12*"AWS12, cubert" $^{\prime *}(-$ 3054.06) + FRA9*"FRA6, cubert"*1096.85 + FRA6*FRA12*2849.28 + FRA9*"FRA9, cubert $^{\prime *} 855.393$ + FRA9*(G-sec120)*136.537 + (G-sec60)*"G-sec120, cubert"*38.766 + FRA9*"AWS12, cubert"*2699.42 + "IRS 2 weeks"*"AWS12, cubert"*(-983.332) + FRA9* $(\mathrm{G}-\sec 36) * 3408.87$ + FRA12*(G-sec24)*2260.99 + FRA12*(G-sec36)*(-2322.19) + FRA12*(G-sec60 $)^{*} 88.0302+(\mathrm{G}-\sec 36)^{*}(\mathrm{G}-\sec 60)^{*}(-86.7214)+$ " "IRS 1 week", cubert $^{\prime * \prime \prime \prime \prime I R S ~} 1$ day", cubert"*7.80931 + (G-sec36)*"FRA12, cubert"*185.09 + (Gsec24)*"FRA9, cubert"*393.139 + "IRS 1 week"*409.292 + FRA9*(G-sec24)*(-1958.68) + "CDS60, cubert"*" "IRS 1 day", cubert"*6.17441 + FRA12*"G-sec120, cubert"*535.873 + $(\mathrm{G}-\mathrm{sec} 24)^{\wedge} 2 * 141.314+(\mathrm{G}-\mathrm{sec} 24)^{* \prime} \mathrm{AWS12}$, cubert"*164.121 + "FRA9, cubert"*84.333 + “FRA6, cubert"*"FRA12, cubert"* $(-225.037)+(\mathrm{G}-\mathrm{sec} 12)^{\wedge} 2 * 61.1704+(\mathrm{G}-\mathrm{sec} 120)^{\star \prime \prime \prime}$ IRS 1 day", cubert"*(-11.4061)

${ }^{*}$ Cubert - Cube root

\section{Phase 3 - Credit Pit Identification}

To find out the credit crash thresholds, a credit pit model was generated on the basis of CDS, FRA and VCAC. The reason for choosing CDS an FRA is due to its impact on other variables and frequency of use in French economy as well as its relation with the financial crisis. FRA 6 is found to be of most impact (either driver or driven) among the other FRA and IRS when seen through granger causality results.

First order differentials are calculated for all the three variables. The correlation among the variables as well as their differentials is given below.

It is interesting to see that, in Table 1, the correlation between CDS and FRA is very high while that of others is not much significant. On the other hand, the correlation between CDS and VCAC and 
their differentials is negative, though very minutely. Thus, indicating CDS and VCAC are inversely proportional, so is the relation between VCAC and FRA.

Table 1 Cross correlation

\begin{tabular}{lr}
\hline \multicolumn{1}{c}{ Correlation Between } & Value \\
\hline CDS 60 - FRA 6 & 0.8048 \\
CDS 60 - VCAC & -0.0494 \\
VCAC - FRA 6 & 0.1713 \\
d/dt CDS 60 - d/dt FRA 6 & 0.1537755 \\
d/dt CDS 60 - d/dt VCAC & -0.00796 \\
d/dt VCAC - d/dt FRA 6 & -0.035852 \\
\hline
\end{tabular}

After finding the first level differentials for all the three variables, a visual graph is obtained using Minitab software to identify the credit pits. In the figure, deep depression is visible, called credit pit. This is during the time when the VCAC collapse because of certain events in the economy or worldwide. The threshold limit is found to be a point when the VCAC is at -4510 . Hence, we find out that there are 15 observations which cross the threshold leading to the deepest point of the pit at -17966 .

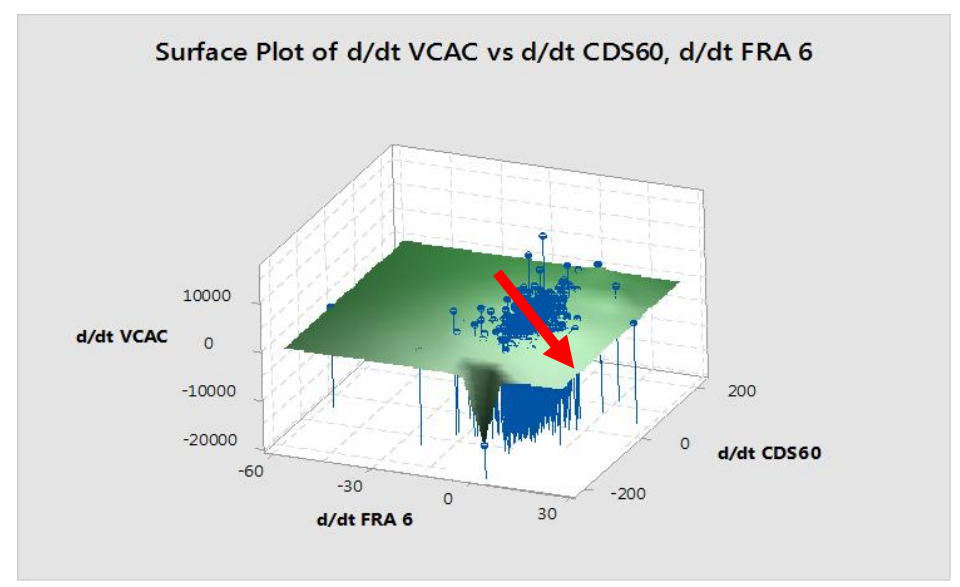

Fig 5: Surface plot for credit pit identification (Threshold is -4510) 


\section{Phase 4 - Behavioural Events linked to identified Credit Pits}

After identification of credit pit and the threshold, in this phase, the credit pits were tracked back to the dates they happened on. Thus, the researchers were able to link back the dates of the credit crunch to particular scenarios causing them.

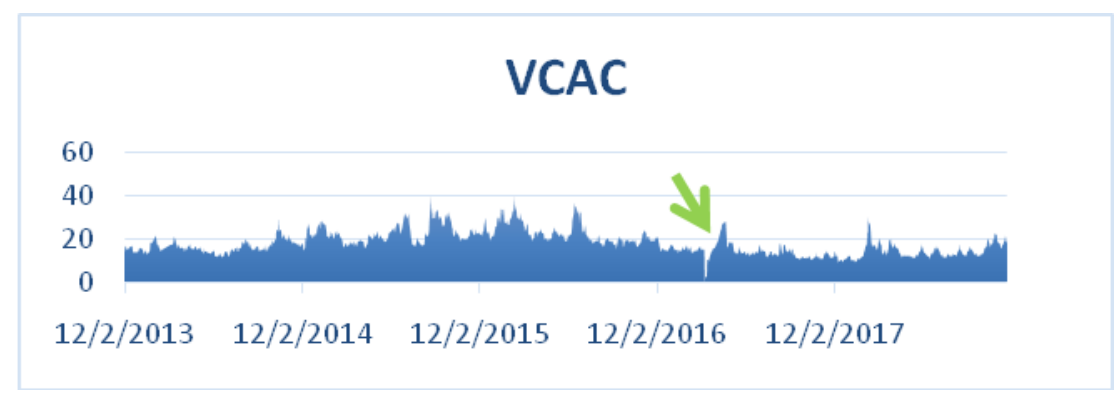

Fig 6: VCAC movement

Figure 6 shows the movement of volatility index with time. We observed a very deep depression on the right side of the graph. This is the point of the credit pit was at its lowest. And from the table below, we see that it happened on 9th March 2017 when Donald Tusk was elected as President of European Council against the wishes of his home country Poland. Thus, it impacts the whole of Eurozone. It is also seen that the threshold of the credit pit (4510) was observed on 17th Feb 2016 which happened due to both the aftermath of Greece debt crisis and migration crisis.

Table 5.4 Credit Pit Corresponding Events

\begin{tabular}{lll}
\hline Date & $\begin{array}{l}\text { d/dt } \\
\text { VCAC }\end{array}$ & Event \\
\hline $17-10-2014$ & -7264.104 & $\begin{array}{l}\text { France publishes a budget for 2015 that } \\
\text { includes 21bn Euros worth of cuts in public } \\
\text { spending, but which still envisages a } \\
\text { budget deficit of 4.3\% - way above the EU } \\
\text { target figure of 3\% of GDP. }\end{array}$ \\
It-12-2014 & -5111.916 & $\begin{array}{l}\text { It was the first European Council chaired by } \\
\text { Donald Tusk as President and it followed a } \\
\text { shorter format, a 'one- day summit'. } \\
\text { Greek crisis: Eurozone leaders held an } \\
\text { emergency summit }\end{array}$ \\
\hline
\end{tabular}




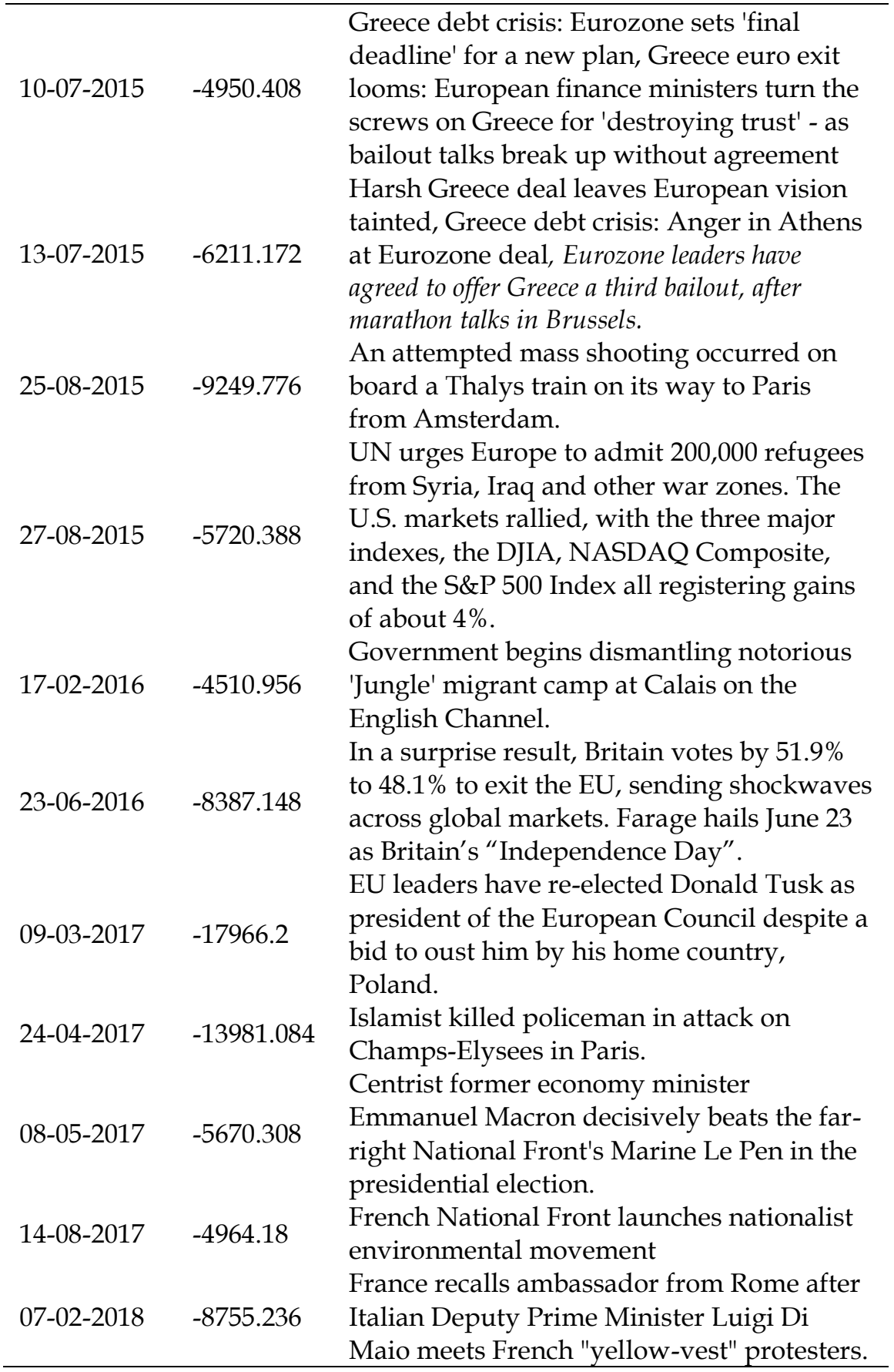


Thus, by identifying a threshold, we can predict when and if a credit event might occur.

\section{Conclusion}

The financial crisis has been known to shake the economies and world at large if the past is any indication of that. 2008 credit crisis, sovereign debt crisis, financial collapse across the world, Venezuelan crisis etc, all have left a lasting impact on the financial domain of the world. Thus, it becomes imperative to not only do mitigative checks and post-crisis smoothening but also to identify the crisis beforehand and take measures to prevent it or safeguard the economy at the very least. Thus, this research aimed at finding a predictor credit pit model for the prevention of financial crisis in France. This CDS - FRA based model is successful in identifying the threshold for France's volatility impact just before it starts to create a heavy impact in terms of a market crash.

The study found that in France, the credit threshold for volatility index (VCAC) is at - 4510. Thus, when the VCAC should touch this mark, it is an indication towards probable crisis and to be looked upon to prevent the crisis from happening. This model proves to be a preventive model for France Credit crunch. With the help of ANN, the accuracy of the predictive model is also checked and since its neural network, it is built in to be self - correcting and autoregressive in nature. Certain events are seen to be at play which impact the economy heavily is observed to correspond to the dates which are found by this model to be relating to credit pit. Few such events are Greece crisis, Syrian migration, Presidential election, the announcement of Brexit, terrorist attacks etc.

\section{Further Scope of Research}

This model, thus, proves to be of importance in the relevant scenarios of prediction of crisis. However, there still exists the possibility of extending this model to new dimensions to suit the nature of the economy or the financial instruments used. There are also many possibilities of developing similar models with different variables or similar model can be applied in real life using highfrequency data for a more accurate and prompt analysis of current 
market conditions and thus taking a preventive measure against credit crashes.

These types of models have further potential to be developed into creating an alarm system for financial distress. They can also be replicated in other domains that govern the economies.

\section{References}

Baudchon, H. (2017). Overview of French Economy. Eco Flash - BNP Paribas. Retrieved from

economic-research.bnpparibas.com

Bianchetti, M. (2011). The Zeeman effect in astrophysics. Physica, 33(1), 102-121. https://doi.org/10.1016/0031-8914(67)90263-7

Brunnermeier, M. K. (2008). Deciphering the liquidity and credit crunch 2007-08. SSRN, 23(1), 77-100. https://doi.org/10.2139/ssrn.1317454

De Grauwe, P. (2010). The Financial Crisis and the Future of the Eurozone. Bruges European Economic Policy (BEEP) Briefing 21/2010, 21. Retrieved from http://aei.pitt.edu/58454/

Delatte, A.-L., Gex, M., \& López-Villavicencio, A. (2012). Has the CDS market influenced the borrowing cost of European countries during the sovereign crisis? Journal of International Money and Finance, 31(3), 481-497. https:/ / doi.org/10.1016/J.JIMONFIN.2011.10.008

Dickinson, E. (2008). Credit default swaps: so dear to us, so dangerous. SSRN, 1-28. https://doi.org/10.2139/ssrn.1315535

Scheicher, M., Peltonen, T., D'Errico, M. \& Battison, S. (2017). How does risk flow in the credit default swap market? European Central Bank, Working Paper-2041.

Etienne, D. (2009). The current financial crisis and its effects on the French economy, 45. Retrieved from http://miun.diva-portal.org/ smash/get/ diva 2:302360/FULLTEXT01.pdf

Fernández-Villaverde, J., Garicano, L., \& Santos, T. (2013). Political Credit Cycles: The Case of the Eurozone. Journal of Economic Perspectives, 27(3), 145-166. https://doi.org/10.1257/jep.27.3.145

Fontana, A., \& Scheicher, M. (2010). An analysis of euro area sovereign CDS and their relation with government bonds by Alessandro Fontana working paper series no 1271/december 2010/an analysis of euro area sovereign cds and their re. ECB Working Paper, (12).

Ghosh, B. (2017). FRA-CDS-VDAX based credit crash model: A German conundrum. International Journal of Economic Research, 14(8), 221-228. https:// doi.org/10.1364/JOSAA.18.002491

Gourévitch, B., Le Bouquin-Jeannès, R., \& Faucon, G. (2006). Linear and 
nonlinear causality between signals: methods, examples and neurophysiological applications. Biological cybernetics, 95(4), 349-369.

Granger, C. W. J. (1969). Investigating Causal Relations by Econometric Models and Cross-spectral Methods. Econometrica, 37(3). https://doi.org/ http:// dx.doi.org/10.1787/5js33lfw0xxn-en.

Howarth, D. (2013). France and the international financial crisis: The Legacy of State-led Finance David. Governance, 1-44.

Kalbaska, A., \& Gątkowski, M. (2012). Eurozone sovereign contagion: Evidence from the CDS market (2005-2010). Journal of Economic Behavior \& Organization, 83(3), 657-673. https://doi.org/ 10.1016/ J.JEBO.2012.05.010

Kolstad, M. (2013). An analysis of Eurozone sovereign credit default swap.pdf, (August 15,2013), 112.

Lane, P. R. (2012). The European sovereign debt crisis. Journal of Economic Perspectives, 26(3), 49-68. https:/ / doi.org/10.1257/jep.26.3.49

Mehta, N. (2016). CDS bond-basis tightens as sentiment improves. Markit Commentary.

Pereda, E., Quiroga, R. Q., \& Bhattacharya, J. (2005). Nonlinear multivariate analysis of neurophysiological signals. Progress in Neurobiology, 77(1-2), 1-37. https://doi.org/ 10.1016/j.pneurobio. 2005.10.003

Pu, X., \& Zhang, J. (2012). Sovereign CDS Spreads, Volatility, and Liquidity: Evidence from 2010 German Short Sale Ban. Financial Review, 47(1), 171-197. https://doi.org/10.1111/j.1540-6288.2011 00325.x

Stulz, R. M. (2009). Credit Default Swaps and the credit crisis. SSRN, 24(1), 73-92. https://doi.org/10.2139/ssrn.1475323

Taylor, J. B. (2009). The financial crisis and the policy responses. NBER Working Paper, 23(January), 1-19. https://doi.org/ 10.1108/ 13581980 911004352

Ters, K., \& Urban, J. (2016). The transmission of Euro area sovereign risk Contagion: evidence from intraday CDS and Bond markets. SSRN. https://doi.org/10.2139/ssrn.2865894

Wyplosz, C. (2010). The Eurozone in the Current Crisis. SSRN, (207). https:// doi.org/10.2139/ssrn.1589990

CONT, R. (2010). Credit default swaps and financial stability. Financial Stability Review -Banque de France.

Zhang, G., Eddy Patuwo, B., \& Y. Hu, M. (1998). Forecasting with artificial neural networks:: The state of the art. International Journal of Forecasting, 14(1), 35-62. https://doi.org/https:// doi.org/ 10.1016/ S0169-2070(97)00044-7 